\title{
How to overcome taxonomical problems in the study of Internet use disorders and what to do with "smartphone addiction"?
}

\author{
CHRISTIAN MONTAG ${ }^{1,2} *$, ELISA WEGMANN ${ }^{3}$, RAYNA SARIYSKA $^{1}$, ZSOLT DEMETROVICS $^{4}$ and MATTHIAS BRAND ${ }^{3,5}$ \\ ${ }^{1}$ Molecular Psychology, Institute for Psychology and Education, Ulm University, Ulm, Germany \\ ${ }^{2}$ neuSCAN Laboratory, The Clinical Hospital of the Chengdu Brain Science Institute and Key Laboratory for Neuroinformation, \\ University of Electronic Science and Technology of China, Chengdu, China \\ ${ }^{3}$ General Psychology: Cognition and Center for Behavioral Addiction Research (CeBAR), University of Duisburg-Essen, \\ Duisburg, Germany \\ ${ }^{4}$ Institue of Psychology, ELTE Eötvös Loránd University, Budapest, Hungary \\ ${ }^{5}$ Erwin L. Hahn Institute for Magnetic Resonance Imaging, Essen, Germany
}

(Received: August 8, 2019; revised manuscript received: September 26, 2019; accepted: September 27, 2019)

\begin{abstract}
Aims: The present theoretical paper introduces the smartphone technology as a challenge for diagnostics in the study of Internet use disorders and reflects on the term "smartphone addiction." Methods: Such a reflection is carried out against the background of a literature review and the inclusion of Gaming Disorder in ICD-11. Results: We believe that it is necessary to divide research on Internet use disorder (IUD) into a mobile and non-mobile IUD branch. This is important because certain applications such as the messenger application WhatsApp have originally been developed for smartphones and enfold their power and attractiveness mainly on mobile devices. Discussion and conclusions: Going beyond the argumentation for distinguishing between mobile and non-mobile IUD, it is of high relevance for scientists to better describe and understand what persons are actually (over-)using. This is stressed by a number of examples, explicitly targeting not only the diverse contents used in the online world, but also the exact behavior on each platform. Among others, it matters if a person is more of an active producer of content or passive consumer of social media.
\end{abstract}

Keywords: Internet addiction, smartphone addiction, Internet use disorder, smartphone use disorder, problematic Internet use, problematic smartphone use

\section{THE RISE OF THE SMARTPHONE}

Smartphones are ubiquitously available around the world globally. At present, a staggering 3.3 billion smartphone users have been counted worldwide. In other words, more than one third of the human mankind has mobile access to the Internet (statista.com, 2019). Without doubt, the wide distribution of smartphones has many advantages including the easy access to information, the better possibilities to communicate, and navigation opportunities, just to mention a few. Aside from these positive effects, many researchers call attention to the detrimental effects of smartphone (over-)use (e.g., Elhai, Levine, Dvorak, \& Hall, 2016; Elhai, Yang, \& Montag, 2019; Gao, Xiang, Zhang, Zhang, \& Mei, 2017; Gligor \& Mozoş, 2019; Montag \& Becker, 2019). Billieux, Maurage, Lopez-Fernandez, Kuss, and Griffiths (2015) propose different pathways to describe the formation of problematic smartphone use (e.g., excessive reassurance pathway) as well as different negative consequences, which can arise from this use. Among the risk factors, personality (e.g., low self-control or emotional instability) and psychopathology (e.g., ADHD or antisocial personality) have been put forward. Elhai, Levine, and
Hall (2019) developed a theoretical framework, based on the Compensatory Internet Use Theory by KardefeltWinther (2014), where (problematic) smartphone use is described as a regulatory strategy to reduce negative emotion (anxiety). However, more elaborate theoretical frameworks are still missing. Among the consequences of smartphone (over-)use, there are problems with being inattentive to the traffic due to interaction with the smartphone (Billieux, Maurage, et al., 2015), loss of productivity due to constant interruptions (Duke \& Montag, 2017b) but also being less concentrated on work-related tasks due to the mere "presence" of the smartphone on the work desk (Ward, Duke, Gneezy, \& Bos, 2017). Moreover, research by Kushlev, Proulx, and Dunn (2016) as well as by Hadar et al. (2017) suggests that high-frequency smartphone use could result in ADHD-like tendencies. Dey et al. (2019) observe similar links to ADHD, but also to social anxiety.

\footnotetext{
* Corresponding author: Prof. Dr. Christian Montag; Institute of Psychology and Education, Zentrum für Biomedizinische Forschung, Ulm University, Helmholtzstr. 8/1, D-89081 Ulm, Germany; Phone: +49 73150 26550; Fax: +49 73150 32759; E-mail: mail@ christianmontag.de
}

This is an open-access article distributed under the terms of the Creative Commons Attribution-NonCommercial 4.0 International License, which permits unrestricted use, distribution, and reproduction in any medium for non-commercial purposes, provided the original author and source are credited, a link to the CC License is provided, and changes - if any - are indicated. 
Dwyer, Kushlev, and Dunn (2018) also demonstrate that the presence of the smartphone might even result in a lower enjoyment of daily face-to-face interaction, probably also having detrimental effects on empathy (Lachmann et al., 2018). In addition, smartphone (over-)use is associated with poorer academic outcomes as well as superficial learning approaches (Rozgonjuk, Saal, \& Täht, 2018; Samaha \& Hawi, 2016). Moreover, aggressive behavior (cyberbullying; Billieux, Maurage, et al., 2015), irregular eating patterns (meal skipping; Kim \& Kim, 2015), and lower physical activity (Kim, Kim, \& Jee, 2015) are associated with problematic smartphone use. A new work by Grant, Lust, and Chamberlain (2019) links problematic smartphone use to poorer academic performance, affective disorders, and alcohol use disorder. Further physiological consequences are poorer sleep quality (Demirci, Akgönül, \& Akpinar, 2015; Liu et al., 2017; Xie, Dong, \& Wang, 2018) as well as neck pain and pain in the hand (AlAbdulwahab, Kachanathu, \& AlMotairi, 2017; İnal, Demirci, Çetintürk, Akgönül, \& Savaş, 2015) due to excessive smartphone use.

\section{TOWARD AN UNDERSTANDING OF THE RELATIONSHIP BETWEEN INTERNET AND SMARTPHONE USE DISORDER}

Consistent with the inclusion of Gaming Disorder in ICD-11 (WHO, 2019; see also Montag, Schivinski, et al., 2019; Pontes et al., 2019), many researchers switched from using the term Internet addiction to Internet Use Disorder (IUD) to describe the excessive use of the Internet and to find a fit with the terminology used in ICD-11. Therefore, IUD may be understood as predominantly online addictive behaviors, as the ICD-11 distinguishes between predominantly online and predominantly offline specifications of gambling and gaming disorders. Given the wide distribution of smartphone devices in everyday life and the long duration of daily usage (Montag, Błaszkiewicz, et al., 2015), it is understandable that many researchers use the "handy" term smartphone addiction or Smartphone Use Disorder [SmUD; although SUD would be the straightforward abbreviation for SmUD (and has been used earlier in Lachmann, Duke, Sariyska, \& Montag, 2017 or Peterka-Bonetta, Sindermann, Elhai, \& Montag, 2019), in certain contexts SUD might be too easily mistaken as the abbreviation for substance-use disorder. Therefore, we propose from now on to use the abbreviation SmUD] in the context of potential negative effects of smartphone overuse on well-being and productivity in daily life (e.g., Duke \& Montag, 2017a; Gao et al., 2017; Gligor \& Mozoş, 2019; Kwon, Kim, Cho, \& Yang, 2013; Lachmann et al., 2018; Peterka-Bonetta et al., 2019; Samaha \& Hawi, 2016). For a discussion on the "addiction" term in the context of smartphone use, see Panova and Carbonell (2018). Reflecting on disordered use of the Internet, the term Internet use disorder is an improvement over smartphone/Internet addiction because persons might become addicted to certain online channels, hence content, and not to the Internet or the smartphone per se (nevertheless, the smartphone itself can become a learned cue related to all these channels and alone might be able to elicit cuereactivity; see Duke \& Montag, 2017a). However, this terminology is still too imprecise without a clear distinction to the construct and content of IUD.

From our perspective, it is of importance to note that no consensus has been reached on relevant criteria to speak of addictive behavior or Use Disorder related to smartphones (and/or the Internet per se). Prominent self-report inventories, which assess problematic behavior in the realm of smartphone usage - such as the one by Kwon et al. (2013) have been constructed on the background of an addictionframework stressing symptoms such as withdrawal, overuse, and tolerance. Such a framework has also been used to study the prominent sibling Internet addiction/IUD; thus, it comes as no surprise that SmUD and IUD overlap to some extent (for more details, see Duke \& Montag, 2017a; Lachmann et al., 2017). This overlap illustrates the question of commonalities as well as differences between both constructs. However, the aim of the current manuscript is not to address the differences between the IUD and SmUD, which both seem to address the generalized, unspecified overuse of the Internet only using different applications. We rather outline the idea of investigating mechanisms and risk factors of specific content, keeping the different types of access in mind.

Therefore, we suggest two steps that should be taken into consideration when investigating specific IUDs. First, it is important to specify the content or the preferred online application. This is based on the assumptions that specific usage motives and needs, anticipated rewards, and use expectancies could lead to the preference of a specific type of application or content (e.g., Brand, Young, Laier, Wölfling, \& Potenza, 2016; see an update in Brand et al., 2019). It can be assumed that this is independent of the device or its properties. However, on the other hand, we think the devices should not be ignored entirely, since they are characterized by specific behavioral usage patterns, technological features, or preferred for one application or content in general. In ICD-11, Gaming Disorder is differentiated into two categories: Gaming Disorder, predominantly online ( "primarily conducted over the Internet"), and Gaming Disorder, predominantly offline ("not primarily conducted over the Internet"). The categories illustrate that the overall behavior pattern or gaming behavior, respectively, is the key aspect of this disorder and not if gaming appears online or offline. We think this is also an appropriate approach when addressing the different devices by still focusing on the behavior patterns and not on the devices. Therefore, two forms of IUD should be considered: IUD, predominantly mobile and IUD, predominantly non-mobile. Both respective areas must then be described in more detail with respect to the actual content excessively used by online users under investigation (see Figure 1). Note that the proposed taxonomy still takes into account the classical concepts of specific IUD (where the Internet is used excessively with a focus on only one type of content) and generalized, unspecified IUD (where one might overuse several channels with diverse contents) as described by Davis (2001). Based on this argumentation, it could be concluded that SmUD can be used synonymously with generalized, unspecified IUD, predominantly mobile via a smartphone.

In the following, we elaborate more on how our taxonomy should be understood, also in the context of new technologies 


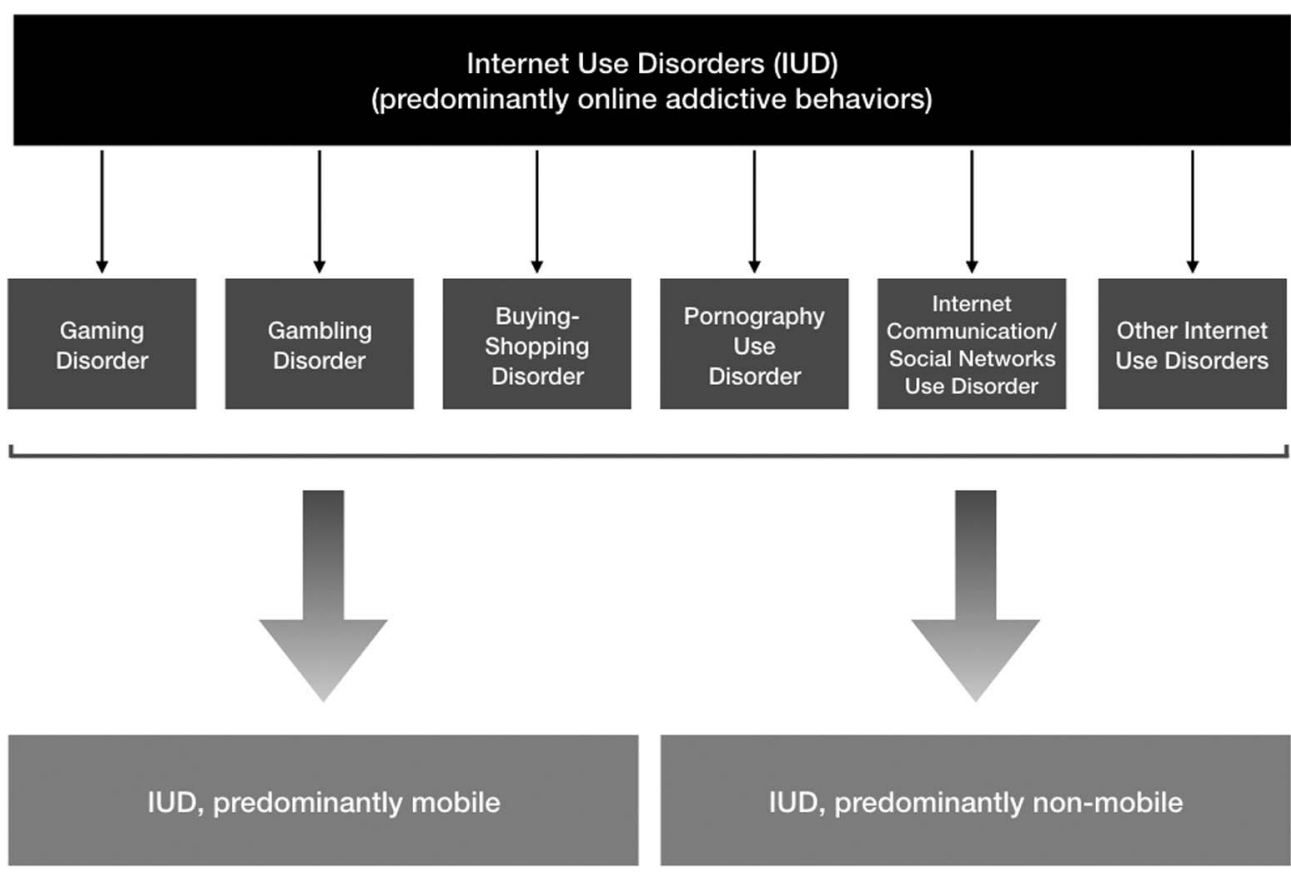

Figure 1. A taxonomy of Internet Use Disorders. In short, IUD can be split into a predominantly mobile and a predominantly non-mobile form, whereas both respective areas need to be additionally characterized by the kind of content (overused)

to appear in the future. Addressing the suggestions in line with earlier efforts to better understand IUD, the time has come to not only speak of a category such as an IUD, predominantly mobile, but also the interaction of application and device to answer what kind of content persons are probably overusing on which mobile devices (and this might overlap with categories of IUD developing via desktop or laptop computers). On smartphones, currently perhaps the most prominent representative of the mobile device category and IUD, predominantly mobile, clearly social media/ network applications such as WhatsApp or Instagram are of high importance to understand how a person is communicating via these devices (e.g., Montag, Błaszkiewicz, et al., 2015; Sha, Sariyska, Riedl, Lachmann, \& Montag, 2019). Although the broader term Social Media Use Disorder (or Social Media Disorder, respectively) has also been used by several researchers (e.g., van den Eijnden, Lemmens, \& Valkenburg, 2016), we prefer the term Social Networks Use Disorder to make explicit that the communication behavior and social networking are central to this type of IUD and not the use of other types of social media, such as reading/writing recommendations or commenting on videos, or contributing to social-media-learning platforms. The idea of dysfunctional communication behavior is also reflected in the term Internet Communication Disorder (ICD), which we used in the past.

\section{THE USED ONLINE CONTENT MATTERS TO BETTER UNDERSTAND IUD ESPECIALLY WHEN INVESTIGATING IT IN GENERAL}

To make things even more complicated for researchers, some of these applications have originally been developed for the smartphone and are now available for desktop computers or other platforms. In contrast, the Facebook application was originally developed for the desktop computer and is now available as a smartphone application. Given the history of each application, it also becomes clear, why many persons likely answer a Smartphone Addiction Questionnaire while thinking of WhatsApp and only to a lesser extent of Facebook, because the latter platform stems from times where the smartphone - as we today know it - did not exist (Sha et al., 2019). Such thinking style probably is also dependent on the age and the own Internet use history of each user.

This said, not only Internet-communication applications are popular on smartphones, but clearly also smartphone games such as Pokémon (e.g., Andone, Blaszkiewicz, Böhmer, \& Markowetz, 2017). The development of Freemium ["Freemium games" is a mix of the words premium and free game. The game can be downloaded at no costs, but app-in buys are possible to get access to further functions/ advantages while playing the game (Montag, Lachmann, Herrlich, \& Zweig, 2019)] games has become a billiondollar industry for a reason and mirrors the popularity of gaming on smartphones. The Freemium game Candy Crush Saga alone has been downloaded an unbelievable 2.7 billion times (https://mashable.com/category/candy-crush/; accessed on May 27, 2019). Probably - and further stressing the importance to distinguish between IUD, predominantly mobile and non-mobile, keeping the device in mind when investigating Gaming Disorder - these games could be much more addictive than the "classic" computer games played on a desktop computer and/or a console (for mechanisms prolonging play time of Freemium games, please see Montag, Lachmann, et al., 2019; for an overlap between SmUD and Gaming Disorder, see Leung et al., 2019). In this context, we also mention that some of these games can be played without Internet connection; therefore, SmUD is a phenomenon to be discussed in the "offline" area, too.

In general, questionnaires asking a person how strong the impact of the smartphone and Internet is on their lives are rather of unspecified than generalized nature, because a 
person mostly using online gaming applications might think of games when filling in such a questionnaire. In contrast, other persons indeed might think in the same situation of different applications, ergo using the Internet in multipurpose ways. Clearly, the research field has to find a consensus on how many of these channels should be overused (and in what manner) to be able to speak of a generalized/ unspecified IUD, non-mobile or mobile (SmUD; hence, generalized/unspecified mobile IUD). Concerning a person's (over-) use of different online contents/channels to be assessed, we are convinced that most of the available content of existing online applications falls in the realm of gaming, pornography, communication, gambling, and buying-shopping (Müller et al., 2017), for a more classic work focusing on the correlation between specific and unspecified IUD (please see Montag, Bey, et al., 2015). Clearly, other areas of content exist and we refer to these as "Other Internet Use Disorders" in Figure 1.

Such a detailed view on specific areas of IUD will also help to better clarify the validity of new concepts such as ICD or Social Networks Use Disorder (Montag, Zhao, et al., 2018; Wegmann \& Brand, 2016); see also a new review on the neuroscience of ICD by Wegmann, Müller, Ostendorf, and Brand (2018), describing detrimental effects of excessive online communication on persons' lives (see also Montag, 2019). Different applications could be accessed via different devices, which could have an impact on specific mechanisms of the development or maintenance of such a disorder. However, it should be more important to investigate what are predisposing factors, specific usage motives, as well as cognitive and affective components (such as use expectancies, experienced gratification), leading to an overuse and loss of control over the specific application instead of investigating the importance of the used devices. However, there are some examples, which outline that one application contains different specific contents (e.g., WeChat in China). WeChat has many functions going beyond communication (Montag, Becker, \& Gan, 2018). This also illustrates the importance to take a detailed look at what functions a person is using of an application to better understand if a certain area falls in the context of IUD (Rothen et al., 2018). Finally, we point to the relevance to distinguish between active or passive use in the realm of social media applications with passive use more linked to envy and detrimental social comparison processes (e.g., Appel, Gerlach, \& Crusius, 2016).

\section{USAGE OF THE INTERNET IS NOT PER SE GOOD OR BAD, BUT THE KIND OF USAGE AND CONTEXT MATTERS}

It is important to note that research from Billieux, Schimmenti, Khazaal, Maurage, and Heeren (2015) hinted toward the significant point that researchers should be aware not to overpathologize everyday life. We agree with this notion and believe that technology per se is neither good nor bad, but the way and the context of technology use matter (see also Montag \& Walla, 2016; Montag \& Diefenbach, 2018). To better understand the impact of IUD on our psyches and well-being, it will be of importance to take into account what kind of device (mobile/non-mobile) with what kind of applications (gaming, gambling, etc.) in what kind of context (private vs. business, family vs. colleagues, etc.) is used and how often. Furthermore, constantly checking (the frequency) WhatsApp (the application) on the smartphone (a mobile device) at a wedding (the context) in many cultural settings will not be appropriate in terms of a digital etiquette. Bringing together these different dimensions might help to get to a more fine-grained understanding of when technology use has negative influences on our lives.

\section{FUTURE DIRECTIONS}

Although smartphones are without doubt the most prominent representative of the current way to access the mobile Internet (hence the driving force behind mobile IUD), meanwhile many persons can also get distracted via their own smartwatch or their tablet. For an example, a recent study by Giang, Shanti, Chen, Zhou, and Donmez (2015) compares the impact of checking the smartphone vs. smartwatch while driving a car. In sum, online content can be accessed via manifold devices. Hence, we are convinced that it is of relevance to distinguish in upcoming IUD research between mobile devices (smartphones, smartwatches, and tablets) to access the Internet or non-mobile devices such as desktop computers/laptops. Laptop computers fall somewhere in between the categories. At present, we would put them rather in the latter category, because they are usually larger than smartphones and tablets and cannot be that easily carried around compared to a smartwatch or a smartphone. IUD, predominantly mobile, might then function as an umbrella term describing problem behavior in the context of accessing the Internet via devices, which can be easily carried around. The contrary is true for IUD, predominantly non-mobile. We are optimistic that the proposed terms in this paper also have the advantage to be useful for a longer time period, because new devices such as smart glasses or other inventions might still be covered by our proposed categories. Distinguishing between the use of a mobile vs. non-mobile device to access the Internet is also of importance for another reason when investigating IUD. We believe that the mere opportunity to go online plays an important role for researchers to understand how and why excessive Internet use behavior might develop. As in the early times of the Internet, availability still is an important prerequisite to be able to use and overuse an online technology. With the advent of the smartphone, a person can carry around his or her access to online content on a $24 / 7$ basis.

Funding sources: The position of CM was funded by a Heisenberg grant awarded to him by the German Research Foundation (DFG, MO2363/3-2). ZsD was supported by the Hungarian National Research, Development and Innovation Office (grant number: KKP126835).

Authors' contribution: CM, EW, and MB planned the present debate paper. CM wrote the first draft, which was critically revised by $\mathrm{MB}, \mathrm{EW}, \mathrm{RS}$, and $\mathrm{ZsD}$. 
Conflict of interest: The authors declare no conflict of interest.

Dr. MB has received (to University of Duisburg-Essen) grants from the German Research Foundation (DFG), the German Federal Ministry for Research and Education, the German Federal Ministry for Health, and the European Union. He has performed grant reviews for several agencies; has edited journal sections and articles; has given academic lectures in clinical or scientific venues; and has generated books or book chapters for publishers of mental health texts.

Dr. CM has received (to Ulm University and earlier University of Bonn) grants from the German Research Foundation (DFG) and the German Federal Ministry for Research and Education. He has performed grant reviews for several agencies; has edited journal sections and articles; has given academic lectures in clinical or scientific venues or companies; and has generated books or book chapters for publishers of mental health texts. For some of these activities, he received royalties, but never from the gaming or social media industry. Finally, he mentions that he is part of a discussion circle on social media and democracy at Facebook. In this context, he receives no salary for his activities from Facebook, but his travel costs have been reimbursed.

\section{REFERENCES}

Appel, H., Gerlach, A. L., \& Crusius, J. (2016). The interplay between Facebook use, social comparison, envy, and depression. Current Opinion in Psychology, 9, 44-49. doi:10.1016/ j.copsyc.2015.10.006

AlAbdulwahab, S. S., Kachanathu, S. J., \& AlMotairi, M. S. (2017). Smartphone use addiction can cause neck disability. Musculoskeletal Care, 15(1), 10-12. doi:10.1002/msc.1170

Andone, I., Blaszkiewicz, K., Böhmer, M., \& Markowetz, A. (2017). Impact of location-based games on phone usage and movement: A case study on PokéMon GO. Paper presented at Proceedings of the 19th International Conference on HumanComputer Interaction with Mobile Devices and Services, ACM, Vienna, Austria.

Billieux, J., Maurage, P., Lopez-Fernandez, O., Kuss, D. J., \& Griffiths, M. D. (2015). Can disordered mobile phone use be considered a behavioral addiction? An update on current evidence and a comprehensive model for future research. Current Addiction Reports, 2(2), 156-162. doi:10.1007/s40429015-0054-y

Billieux, J., Schimmenti, A., Khazaal, Y., Maurage, P., \& Heeren, A. (2015). Are we overpathologizing everyday life? A tenable blueprint for behavioral addiction research. Journal of Behavioral Addictions, 4(3), 119-123. doi:10.1556/2006.4. 2015.009

Brand, M., Wegmann, E., Stark, R., Müller, A., Wölfling, K., Robbins, T. W., \& Potenza, M. N. (2019). The Interaction of Person-Affect-Cognition-Execution (I-PACE) model for addictive behaviors: Update, generalization to addictive behaviors beyond Internet-use disorders, and specification of the process character of addictive behaviors. Neuroscience and Biobehavioral Reviews, 104, 1-10. doi:10.1016/j.neubiorev. 2019.06.032
Brand, M., Young, K. S., Laier, C., Wölfling, K., \& Potenza, M. N. (2016). Integrating psychological and neurobiological considerations regarding the development and maintenance of specific Internet-use disorders: An Interaction of PersonAffect-Cognition-Execution (I-PACE) model. Neuroscience and Biobehavioral Reviews, 71, 252-266. doi:10.1016/ j.neubiorev.2016.08.033

Davis, R. A. (2001). A cognitive-behavioral model of pathological Internet use. Computers in Human Behavior, 17(2), 187-195. doi:10.1016/S0747-5632(00)00041-8

Demirci, K., Akgönül, M., \& Akpinar, A. (2015). Relationship of smartphone use severity with sleep quality, depression, and anxiety in university students. Journal of Behavioral Addictions, 4(2), 85-92. doi:10.1556/2006.4.2015.010

Dey, M., Studer, J., Schaub, M. P., Gmel, G., Ebert, D. D., Lee, J. Y. C., \& Haug, S. (2019). Problematic smartphone use in young Swiss men: Its association with problematic substance use and risk factors derived from the pathway model. Journal of Behavioral Addictions, 8(2), 326-334. doi:10.1556/2006.8.2019.17

Duke, É., \& Montag, C. (2017a). Smartphone addiction and beyond: Initial insights on an emerging research topic and its relationship to Internet addiction. In C. Montag \& M. Reuter (Eds.), Internet addiction: Neuroscientific approaches and therapeutical implications including smartphone addiction (pp. 359-372). Cham, Switzerland: Springer.

Duke, É., \& Montag, C. (2017b). Smartphone addiction, daily interruptions and self-reported productivity. Addictive Behaviors Reports, 6, 90-95. doi:10.1016/j.abrep.2017.07.002

Dwyer, R. J., Kushlev, K., \& Dunn, E. W. (2018). Smartphone use undermines enjoyment of face-to-face social interactions. Journal of Experimental Social Psychology, 78, 233-239. doi:10.1016/j.jesp.2017.10.007

Elhai, J. D., Levine, J. C., Dvorak, R. D., \& Hall, B. J. (2016). Fear of missing out, need for touch, anxiety and depression are related to problematic smartphone use. Computers in Human Behavior, 63, 509-516. doi:10.1016/j.chb.2016.05.079

Elhai, J. D., Levine, J. C., \& Hall, B. J. (2019). The relationship between anxiety symptom severity and problematic smartphone use: A review of the literature and conceptual frameworks. Journal of Anxiety Disorders, 62, 45-52. doi:10.1016/ j.janxdis.2018.11.005

Elhai, J. D., Yang, H., \& Montag, C. (2019). Maladaptive cognitive and emotion processes: Mechanisms explaining depression and anxiety's relations with problematic smartphone use. Current Addiction Reports. Advance online publication. doi:10.1007/ s40429-019-00260-4

Gao, T., Xiang, Y. T., Zhang, H., Zhang, Z., \& Mei, S. (2017). Neuroticism and quality of life: Multiple mediating effects of smartphone addiction and depression. Psychiatry Research, 258, 457-461. doi:10.1016/j.psychres.2017.08.074

Giang, W. C. W., Shanti, I., Chen, H.-Y. W., Zhou, A., \& Donmez, B. (2015, September). Smartwatches vs. smartphones: A preliminary report of driver behavior and perceived risk while responding to notifications. Paper presented at Proceedings of the 7th International Conference on Automotive User Interfaces and Interactive Vehicular Applications (pp. 154-161), ACM, Nottingham, United Kingdom.

Gligor, Ş., \& Mozoş, I. (2019). Indicators of smartphone addiction and stress score in university students. Wiener klinische Wochenschrift, 131(5-6), 120-125. doi:10.1007/s00508-0181373-5 
Grant, J. E., Lust, K., \& Chamberlain, S. R. (2019). Problematic smartphone use associated with greater alcohol consumption, mental health issues, poorer academic performance, and impulsivity. Journal of Behavioral Addictions, 8(2), 335-342. doi:10.1556/2006.8.2019.32

Hadar, A., Hadas, I., Lazarovits, A., Alyagon, U., Eliraz, D., \& Zangen, A. (2017). Answering the missed call: Initial exploration of cognitive and electrophysiological changes associated with smartphone use and abuse. PLoS One, 12(7), e0180094. doi:10.1371/journal.pone.0180094

İnal, E. E., Demirci, K., Çetintürk, A., Akgönül, M., \& Savaş, S. (2015). Effects of smartphone overuse on hand function, pinch strength, and the median nerve. Muscle \& Nerve, 52(2), 183-188. doi:10.1002/mus.24695

Kardefelt-Winther, D. (2014). A conceptual and methodological critique of Internet addiction research: Towards a model of compensatory Internet use. Computers in Human Behavior, 31, 351-354. doi:10.1016/j.chb.2013.10.059

Kim, E. J., \& Kim, S. Y. (2015). Correlation between smartphone addiction and eating behaviors of elementary school students in Ansan area. Journal of the Korean Society of Food Science and Nutrition, 44(7), 1007-1015. doi:10.3746/jkfn.2015.44.7.1007

Kim, S.-E., Kim, J.-W., \& Jee, Y.-S. (2015). Relationship between smartphone addiction and physical activity in Chinese international students in Korea. Journal of Behavioral Addictions, 4(3), 200-205. doi:10.1556/2006.4.2015.028

Kushlev, K., Proulx, J., \& Dunn, E. W. (2016, May). "Silence your phones": Smartphone notifications increase inattention and hyperactivity symptoms. Paper presented at Proceedings of the 2016 CHI Conference on Human Factors in Computing Systems (pp. 1011-1020), ACM, San Jose, CA, USA.

Kwon, M., Kim, D.-J., Cho, H., \& Yang, S. (2013). The Smartphone Addiction Scale: Development and validation of a short version for adolescents. PLoS One, 8(12), e83558. doi:10.1371/journal.pone. 0083558

Lachmann, B., Duke, É., Sariyska, R., \& Montag, C. (2017). Who's addicted to the smartphone and/or the Internet? Psychology of Popular Media Culture, 8(3), 182-189. doi:10.1037/ppm 0000172

Lachmann, B., Sindermann, C., Sariyska, R. Y., Luo, R., Melchers, M. C., Becker, B., Cooper, A. J., \& Montag, C. (2018). The role of empathy and life satisfaction in Internet and smartphone use disorder. Frontiers in Psychology, 9. doi:10.3389/ fpsyg.2018.00398

Leung, H., Pakpour, A. H., Strong, C., Lin, Y.-C., Tsai, M.-C., Griffiths, M. D., Lin, C.-Y., \& Chen, I.-H. (2019). Measurement invariance across young adults from Hong Kong and Taiwan among three Internet-Related Addiction Scales: Bergen Social Media Addiction Scale (BSMAS), Smartphone ApplicationBased Addiction Scale (SABAS), and Internet Gaming Disorder Scale-Short Form (IGDS-SF9) (Study Part A). Addictive Behaviors. Advance online publication. doi:10.1016/j.addbeh. 2019.04.027

Liu, Q.-Q., Zhou, Z.-K., Yang, X.-J., Kong, F.-C., Niu, G.-F., \& Fan, C.-Y. (2017). Mobile phone addiction and sleep quality among Chinese adolescents: A moderated mediation model. Computers in Human Behavior, 72, 108-114. doi:10.1016/ j.chb.2017.02.042

Montag, C. (2019). The neuroscience of smartphone/social media usage and the growing need to include methods from 'Psychoinformatics'. In F. Davis, R. Riedl, J. vom Brocke,
P. M. Léger, \& A. Randolph (Eds.), Information systems and neuroscience (pp. 275-283). Cham, Switzerland: Springer.

Montag, C., \& Becker, B. (2019). Psychological and neuroscientific advances to understand Internet use disorder. Neuroforum, 25(2), 99-107. doi:10.1515/nf-2018-0026

Montag, C., Becker, B., \& Gan, C. (2018). The multi-purpose application WeChat usage: A review on recent literature. Frontiers in Psychology, 9, 2247. doi:10.3389/fpsyg.2018.02247

Montag, C., Bey, K., Sha, P., Li, M., Chen, Y.-F., Liu, W.-Y., Zhu, Y. K., Li, C. B., Markett, S., Keiper, J., \& Reuter, M. (2015). Is it meaningful to distinguish between generalized and specific Internet addiction? Evidence from a cross-cultural study from Germany, Sweden, Taiwan and China. Asia-Pacific Psychiatry, 7(1), 20-26. doi:10.1111/appy.12122

Montag, C., Błaszkiewicz, K., Sariyska, R., Lachmann, B., Andone, I., Trendafilov, B., Eibes, M., \& Markowetz, A. (2015). Smartphone usage in the 21st century: Who is active on WhatsApp? BMC Research Notes, 8(1), 331. doi:10.1186/ s13104-015-1280-Z

Montag, C., \& Diefenbach, S. (2018). Towards homo digitalis: Important research issues for psychology and the neurosciences at the dawn of the Internet of things and the digital society. Sustainability, 10(2), 415. doi:10.3390/su10020415

Montag, C., Lachmann, B., Herrlich, M., \& Zweig, K. (2019). Addictive features of social media/messenger platforms and freemium games against the background of psychological and economic theories. International Journal of Environmental Research and Public Health, 16(14), 2612. doi:10.3390/ ijerph16142612

Montag, C., Schivinski, B., Sariyska, R., Kannen, C., Demetrovics, Z., \& Pontes, H. (2019). Psychopathological symptoms and gaming motives in disordered gaming: A psychometric comparison between the WHO and APA diagnostic frameworks. Journal of Clinical Medicine, 8, 1691. doi:10.3390/ jem8101691

Montag, C., Zhao, Z., Sindermann, C., Xu, L., Fu, M., Li, J., Zheng, X., Li, K., Kendrick, K. M., Dai, J., \& Becker, B. (2018). Internet communication disorder and the structure of the human brain: Initial insights on WeChat addiction. Scientific Reports, 8(1), 2155. doi:10.1038/s41598-018-19904-y

Montag, C., \& Walla, P. (2016). Carpe diem instead of losing your social mind: Beyond digital addiction and why we all suffer from digital overuse. Cogent Psychology, 3(1), 1157281. doi:10.1080/23311908.2016.1157281

Müller, M., Brand, M., Mies, J., Lachmann, B., Sariyska, R. Y., \& Montag, C. (2017). The 2D:4D marker and different forms of Internet use disorder. Frontiers in Psychiatry, 8, 213. doi:10.3389/fpsyt.2017.00213

Panova, T., \& Carbonell, X. (2018). Is smartphone addiction really an addiction? Journal of Behavioral Addictions, 7(2), 252-259. doi:10.1556/2006.7.2018.49

Peterka-Bonetta, J., Sindermann, C., Elhai, J. D., \& Montag, C. (2019). Personality associations with smartphone and Internet use disorder: A comparison study including links to impulsivity and social anxiety. Frontiers in Public Health, 7, 127. doi:10.3389/fpubh.2019.00127

Pontes, H. M., Schivinski, B., Sindermann, C., Li, M., Becker, B., Zhou, M., \& Montag, C. (2019). Measurement and conceptualization of gaming disorder according to the World Health Organization framework: The development of the Gaming Disorder Test. International Journal of Mental Health and 
Addiction. Advance online publication. doi:10.1007/s11469019-00088-z

Rothen, S., Briefer, J. F., Deleuze, J., Karila, L., Andreassen, C. S., Achab, S., Thorens, G., Khazaal, Y., Zullino, D., \& Billieux, J. (2018). Disentangling the role of users' preferences and impulsivity traits in problematic Facebook use. PLoS One, 13(9), e0201971. doi:10.1371/journal.pone.0201971

Rozgonjuk, D., Saal, K., \& Täht, K. (2018). Problematic smartphone use, deep and surface approaches to learning, and social media use in lectures. International Journal of Environmental Research and Public Health, 15(1), 92. doi:10.3390/ijerph15010092

Samaha, M., \& Hawi, N. S. (2016). Relationships among smartphone addiction, stress, academic performance, and satisfaction with life. Computers in Human Behavior, 57, 321-325. doi:10.1016/j.chb.2015.12.045

Sha, P., Sariyska, R., Riedl, R., Lachmann, B., \& Montag, C. (2019). Linking Internet communication and smartphone use disorder by taking a closer look at the Facebook and WhatsApp applications. Addictive Behaviors Reports, 9, 100148. doi:10.1016/j.abrep.2018.100148

Statista.com. (2019). Number of smartphone users worldwide from 2016 to 2021 (in billions). Retrieved October 15, 2019, from https://www.statista.com/statistics/330695/number-of-smartphoneusers-worldwide/ van den Eijnden, R. J., Lemmens, J. S., \& Valkenburg, P. M. (2016). The Social Media Disorder Scale. Computers in Human Behavior, 61, 478-487. doi:10.1016/j.chb.2016. 03.038

Ward, A. F., Duke, K., Gneezy, A., \& Bos, M. W. (2017). Brain drain: The mere presence of one's own smartphone reduces available cognitive capacity. Journal of the Association for Consumer Research, 2(2), 140-154. doi:10.1086/691462

Wegmann, E., \& Brand, M. (2016). Internet-communication disorder: It's a matter of social aspects, coping, and Internet-use expectancies. Frontiers in Psychology, 7. doi:10.3389/ fpsyg.2016.01747

Wegmann, E., Müller, S. M., Ostendorf, S., \& Brand, M. (2018). Highlighting Internet-communication disorder as further Internetuse disorder when considering neuroimaging studies. Current Behavioral Neuroscience Reports, 5(4), 295-301. doi:10.1007/ s40473-018-0164-7

Xie, X., Dong, Y., \& Wang, J. (2018). Sleep quality as a mediator of problematic smartphone use and clinical health symptoms. Journal of Behavioral Addictions, 7(2), 466-472. doi:10.1556/ 2006.7.2018.40

WHO. (2019). Gaming disorder, predominantly online. Retrieved from https://icd.who.int/browse11/1-m/en\#/http\%3a\%2f\%2fid. who.int $\% 2$ ficd $\% 2$ fentity $\% 2 f 338347362$ 